\title{
DEVELOPMENT AND ANALYSIS OF INVERTED-V MPPT TECHNIQUE FOR PHOTOVOLTAIC SYSTEM
}

\author{
Sheilza Jaina ${ }^{1 *}$, Megha Chambyal ${ }^{2}$ \\ ${ }^{1,2}$ Department of Electronics Engineering, J. C. Bose University of Science and Technology, YMCA, Faridabad, Haryana, India \\ ${ }^{1 *}$ sheilzajain@gmail.com, ${ }^{2}$ meghachambyal@gmail.com
}

\begin{abstract}
Three main factors which affect the efficiency of any Photovoltaic system are, the efficiency of the Photovoltaic pane used, efficiency of the inverter used and efficiency of the maximum power point tracking (MPPT) algorithm used. MPPT techniques are widely used in the Photovoltaic (PV) system to extract the maximum power from the Photovoltaic system. MPPT aims that in any environmental conditions i.e for any irradiation or temperature, maximum possible energy is extracted from PV systems. In this paper, Perturb \& Observe (P\&O), Incremental conductance techniques of MPPT are implemented and analyzed. On the basis of the output voltage, power, current, duty cycle and efficiency of the boost converter, comparison of these techniques has been done. To extract the maximum power from the Photovoltaic system, Inverted-V Method has been developed and compared with Perturb \& Observe, Incremental conductance method with the help of MATLAB Simulink software. In this paper, it has been concluded that Inverted $\mathrm{V}$ methods has more efficiency and performs better as compared to the other two methods. This paper could be beneficial as a quick reference for MPPT users and future research application for PV system.
\end{abstract}

Keyword: Photovoltaic system, Solar system, MPPT, MATLAB and Simulink

\section{Introduction}

Energy sources which rely on fossil fuels, takes a lot of years for their formation and causes negative impacts on the environment due to the mining and burning. There is a need of renewable energy sources that are sustainable and inexhaustible [1]. The most effective solution is to use solar power owing to its abundant availability and easy accessibility. Conversion of solar power into electric power is done through PV panels using photovoltaic effect. The basic structure of Photovoltaic system is given by figure 1. PV panel report efficiency somewhere in between of $10 \%$ to $20 \%$ reckoning on the photoactive material and environmental conditions [2]. Power characteristics of Photovoltaic cell, the main components of PV panels, is non-linear. Power characteristics of any PV panel depends upon temperature and solar irradiation. For enhancing the production of solar PV, most of the time operator can't change the material of panel but it can be enhanced by tuning the sun light intensity of solar panel by MPPT techniques [3]. To optimize the system performance a buck boost converter can be connected with a PV model.

Efficiency of PV panels are mainly affected by the efficiency of the PV panel which is approximately between $8-15 \%$ in commercial PV panels, the efficiency of the maximum power point tracking (MPPT) algorithm which is over $98 \%$ and the efficiency of the inverter which is around 95-98\% [1-3]. It is very difficult to improve the efficiency of the PV panel and the inverter because it depends on the technology available and requires better components which in turns increase the cost of the installation. Tracking of the maximum power point (MPP) can be improved by using easier and simple control algorithm. Moreover, their control algorithms can also be updated in plants which are already in use [4-6].

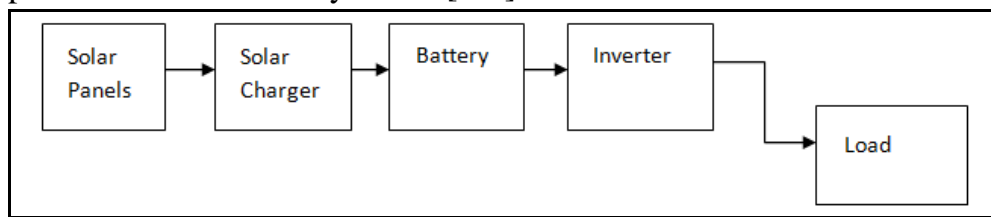

Figure 1. Solar system module

Basically, Maximum Power Point Tracking (MPPT) Techniques are used to withdraw maximum power from the Photovoltaic array during variation of solar irradiance or partial shading conditions. Basic organization of the MPPT system is shown in figure 2. To obtain maximum efficiency, proper matching of $\mathrm{PV}$ generator to load is necessary so that it becomes possible that the operating point coincides with the MPP of PV source.

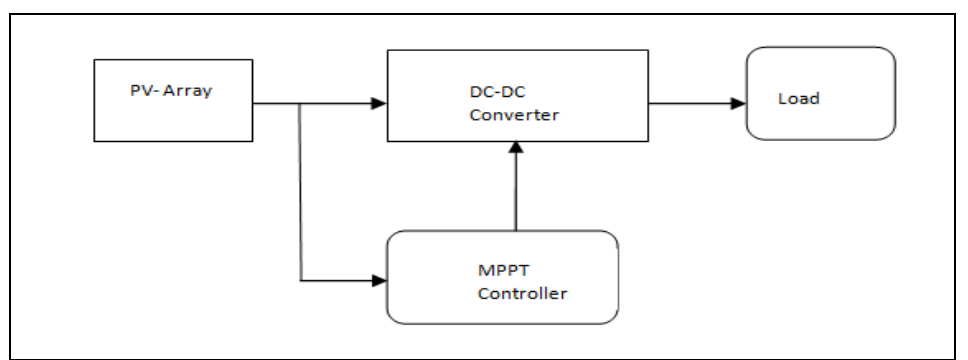

Figure 2 Basic organization of the MPPT based PV system In order to obtained it, DC-DC converter (also known as buck converter) is used between the Photovoltaic array and the load to match their impedance and adjust the voltage-current levels. 
MPPT control algorithms contains two loops; main loop for MPPT and secondary loop for the output protection. During its normal operation, system operates in MPPT mode., but when the load is unable to absorb all the power produced by PV, and when its current or/and voltage exceed beyond the limit., second loop becomes active to control the system. Second loop regulates the output not to exceed the limit [7]. Utility grid or battery is also estimated as constant voltage loads [89]. Maximum Power Point Controller has been used to increase the efficiency. It withdraws maximum power from the PV array and then send it to the load. In order to implement and analyze the behavior of various MPPT techniques, it is necessary to understand the characteristics and model of PV panel/cell which are discussed in the next section.

\section{P-V \& I-V Characteristics of Solar Panel}

Power and Voltage (P-V) and Current and Voltage (I-V ) characteristics of a PV panel are shown in figure 3. As shown by figure, there is a point on the characteristic curve at which the panels functioning permits maximum power. Already existing, PV modules are having low efficiency problems making it is necessary to track this Maximum Power Point (MPP) to use the full power of the PV panel [10-11].

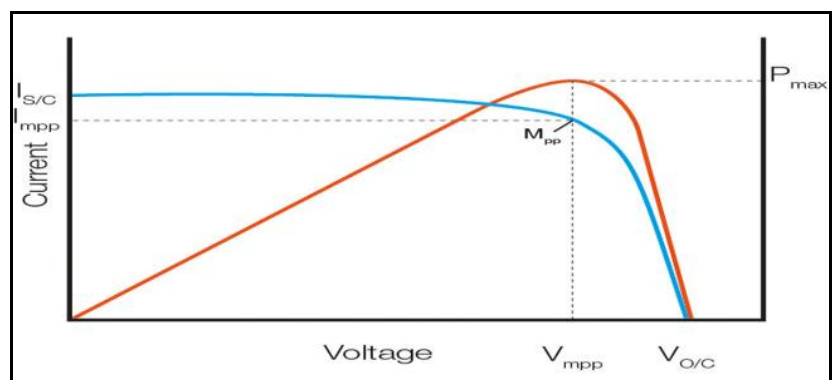

Figure 3 P-V and I-V characteristics of solar panel $[8,10]$

$\mathrm{P}-\mathrm{V}$ and $\mathrm{I}-\mathrm{V}$ characteristics changes as irradiation level and temperature changes. These characteristics given above are check at the standard temperature and irradiation i.e. 25 degree Celsius and $1000 \mathrm{~W} / \mathrm{m} 2$. At the top of the curve, there is MPP. Characteristics of a PV panel/cell for different values of solar irradiation and temperature are given in Figure 4 a) and b) respectively.
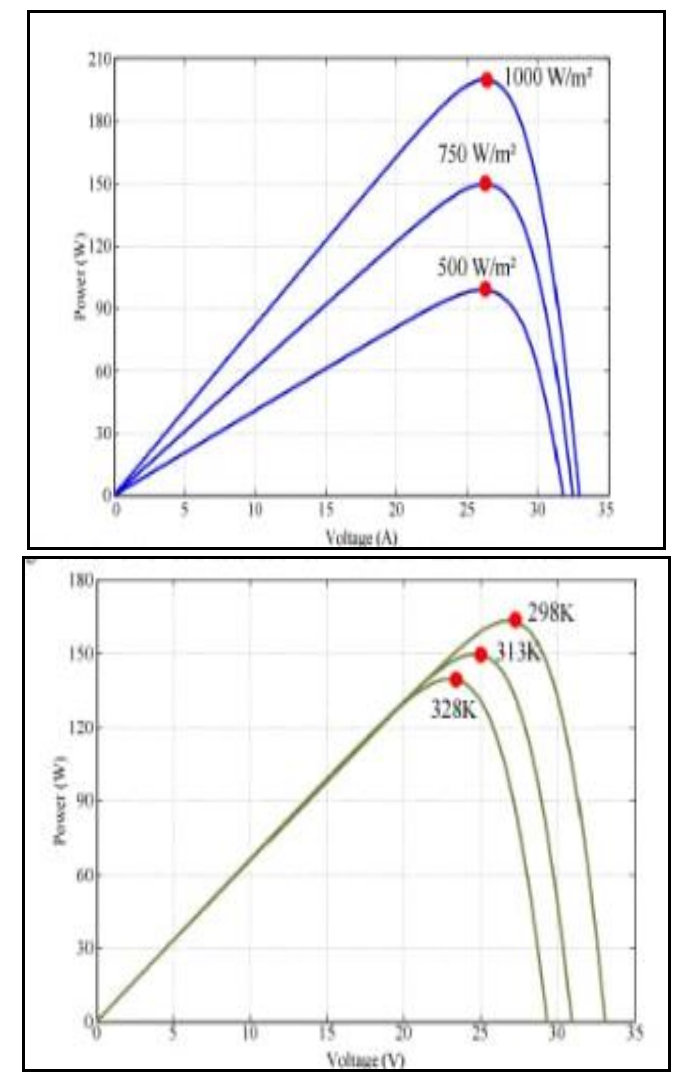

Figure 4 Photovoltaic Power Characteristics for (a) Different Irradiation levels, (b) Different Temperature levels [6]

As depicted from the figures, the non-linear characteristics of PV are strongly affected by the environment changes. The MPPT system is tuned to have a point of operation of the PV panel directly at the high-power point. To achieve this, an effective MPPT strategy must be developed with the following properties such as it must have the ability to attain the global point of MPPT and the tracking speed of MPPT strategy should be high. Slow tracking speed results in decrease in the output power as well as reduces the performance of the photovoltaic system, The MPPT strategy should work properly in any environmental condition whether it is uniform insolation or partial shading, the MPPT strategy should have minimum variations and the MPPT strategy should be able to track the maximum energy of panel even after the sudden changes in irradiation.

\section{Mathematical Modeling of a PV Module}

The circuit diagram of a Photovoltaic cell is given in figure 5 . In this Simplest model, the diode and the current source are connected in parallel. PV cell, the main component of PV panel, has non- linear characteristics due to the insertion of Series and Parallel Resistances i.e. Rs and Rp respectively. This single diode/ cell has following five parameters: Ipv : photovoltaic current, A: diode's ideality factor, Is : diode's saturation current, Rs: series resistance and Rp: shunt resistance. 


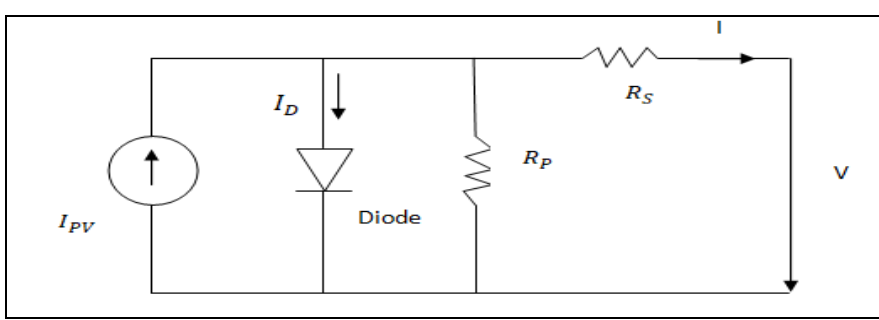

Figure 5 Single Diode Model [6]

$\mathrm{I}-\mathrm{V}$ characteristics of single diode of the PV cell is expressed by the equation given as.

$I=I_{p h}-I_{r^{*}} \cdot\left[e^{q \cdot \frac{V+I \cdot \kappa_{S}}{\eta} k \cdot T}-1\right]-\frac{V+I \cdot R_{S}}{R_{p}}$

(1)

where;

$\mathrm{V}=$ Output voltage of $\mathrm{PV}, \quad I_{p h}=$ Photocurrent, $I_{r}=$ Saturation Current, $\mathrm{q}=$ Electric Charge

$\mathrm{k}=$ Boltzmann Constant , and $\mathrm{T}=$ Temperature in Kelvin

Equation (1) can be altered in order to get a null root, when I react like real Photovoltaic Current.

Then equation (1) will be modified as;

$f(I)=-I-I_{r^{*}}\left[e^{\frac{q \cdot\left(V+I \cdot R_{S}\right)}{\eta \cdot k \cdot T}-1}\right]-\frac{v+I_{0} R_{S}}{R_{p}}$

(2)

Current I whose initial value is null, will be used in the process known as iterative process that approximates equation 2 of its roots. This will be obtained by the Newton - Raphson Method. General Equation of Newton Raphson method is;

$x_{n+1}=x_{n}-\frac{f x_{n}}{f^{J} x_{n}}$

(3)

Derivative of equation 2 is represented in equation shown below;

$f(1)=-1-I_{r^{*}}\left[e^{q \cdot \frac{\left(V+I \cdot R_{S}\right)}{\eta \cdot k \cdot T}}\right] \frac{q \cdot R_{S}}{\eta \cdot k \cdot T}-\frac{R_{S}}{R_{p}}$

The model shown in figure 6 is used as a source voltage, integrator in the model shows the capacitance that will stores the current which is injected in the PV panel.

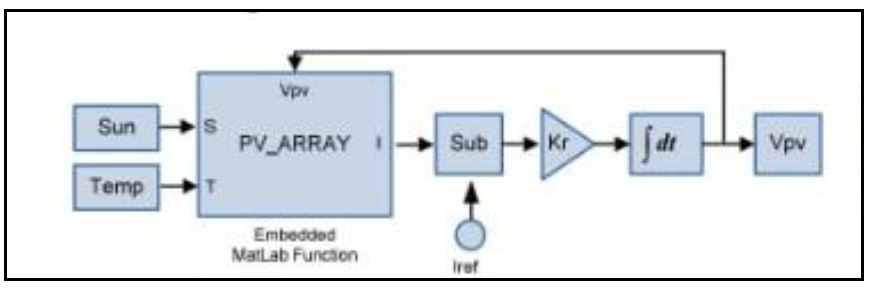

Figure 6 Simulink Model of a Photovoltaic system [6]

\section{Organization of MPPT}

The Maximum Power Point Tracking

(MPPT) Techniques are used to withdraw maximum power from photovoltaic array during variation of solar irradiance or partial shading conditions. There are many types of MPPT techniques. This paper is an attempt to analyze and compare some of the simplest, latest and most commonly used methods of the MPPT algorithm such as Perturb \& Observe (P\&O) method, Incremental \& Conductance(IC) method. In this paper, a new Method known as inverted-V has been introduced which will overcome all the disadvantages of the above algorithms.

All the above methods are studied, implemented and compared in MATLAB Simulink and their efficiency based on parameters like steady state oscillations which are produced at the vicinity of a MPP and their response time has been calculated.

\section{Perturb \& Observe (P\&O) Method}

MPPT is an algorithm to withdraw high power from Photovoltaic array in different environmental conditions. Maximum power point (MPP) is a point at which photovoltaic array delivers high power to the load. This MPP point is also known as Peak Power voltage. In perturb and Observe method, perturbation will be applied. It is used to minimize the parameter control that measures the effect of PV before and after the deviation. By applying perturbation in voltage, power is sensed. If power accelerates, then it will go in the same direction otherwise it will be reversed. If the step size of perturbation is reduced then oscillation can be decreased but this will slow down the process of reaching the Maximum Power Point (MPP). This technique results that when the Perturb and Observe is reached then it starts producing oscillations in the vicinity of the MPP. Disadvantage of this algorithm is that if irradiation changes swiftly then it can easily lose the track of MPP due to which at vicinity of MPP, there exists a steady state error and oscillations are also produced $[2,12]$.

Major drawback of this algorithm is the power loss during the change in environmental conditions. The performance of this method can be enhanced by improving the algorithm of Perturb and Observe (P\&O) by two methods: in first method by examining the process when Perturb and Observe is reached and by comparing the parameters of two preceding cycles. In second method, by changing the step size of perturbation, power loss can be decreased.

The implementation of this $\mathrm{P} \& \mathrm{O}$ Maximum Power Point Method with increasing rate of current perturb has two requirements; First, sampling rates should be high and the value of samples of Voltage and current should reflect the propensity of $\mathrm{P}_{\mathrm{o}}$ when the reference signal is changed for the MPPT power converter.

Second, when the response time of MPPT is fast, frequency should be low. To enhance the performance of the system, comparison between $\mathrm{V}_{\mathrm{pv}} \& \mathrm{I}_{\mathrm{pv}}$ is done. Switch will be turned on with the help of a clock signal and switch 
will be turned off when the actual current reaches at the reference current. Therefore, reference current can be perturbed in every switching cycle as explained above, which means that perturb cycle and switching cycle are equal.

\section{Perturb and Observe Method with fixed perturb}

A new method with modification in $\mathrm{P} \& \mathrm{O}$ method is 'Perturb and Observe with Fixed Perturb' which signifies that fixed perturbation value is employed and it gives rise to reference signal for the second loop of figure 7 . Second loop is the outer control loop. The perturb signal can be array reference V. According to system designs, perturb value is defined. So, solution provided by the Perturb and Observe method is not common and self-reliant. The tracking will be small for smaller perturbation step size whereas the oscillations produced are minimum and vice-versa. Hence, perturb and observe scheme with fixed perturb size will tolerate an immanent tracking-oscillations trade off problem. A Proportional Integral (PI) controller following the MPPT is utilized to curb the power converter. Perturbation size is selected according to inductor size as well as clock (clk) frequency. The $\mathrm{P} \& \mathrm{O}$ method is used in many Photovoltaic systems. P\&O helps in moving operating point towards the MPP. It is used to minimize the parameter control that measures the effect of PV before and after the deviation. By applying perturbation in voltage, power is sensed. When power goes up, the algorithm continues to attack the system on the other side, otherwise the system twists backwards [13]

Figure 7 given below is the Simulink Model of Perturb and Observe. The components used in this model are solar panel, boost converter, sample \& hold circuit, Pulse Width Modulator (PWM) and P\&O algorithm.

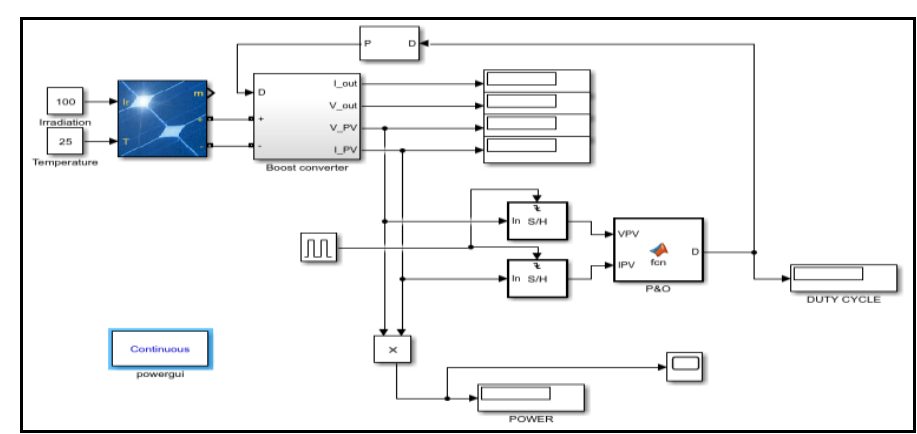

Figure 7 Simulink Model of Perturb and observation Method

\section{Incremental Conductance Method (IC)}

In Incremental Conductance (IC), controller continuously measures the incremental changes in photovoltaic module current and voltage to forecast the effects of change in voltage. In this Method, derivative of Photovoltaic array is null (zero), positive, negative at a point of maximum power (MPP), at the left side of the MPP and at the right side of the MPP respectively. Point of maximum power, MPP can be obtained by comparing the instantaneous conductance $(\mathrm{I} / \mathrm{V})$ operation with continuous boost or instantaneous conductance $(\Delta \mathrm{I} / \Delta \mathrm{V})$ operation. It can work for large-scale tracking of maximum power points under rapidly changing irradiation conditions with high accuracy and can operate directly under rapidly changing environmental conditions [14]. The mathematical relation of this technique is; $\frac{d P}{d t}=\frac{d(V I)}{d V}=\mathrm{V} \frac{d I}{d V}+\mathrm{I}=0$

which implies that

$$
\frac{d I}{d V}=\frac{-I}{V} ;\left(\frac{d P}{d V}=0\right) \text { at point of MPP }
$$

$$
\begin{aligned}
& \frac{d I}{d V}>-\frac{I}{V} ;\left(\frac{d P}{d V}>0\right) \quad \text { at left side of MPP } \\
& \frac{d I}{d V}<-\frac{I}{V} ;\left(\frac{d P}{d V}<0\right) \text { at right side of MPP }
\end{aligned}
$$

Main disadvantage of $\mathrm{P} \& \mathrm{O}$ method to extract maximum power under different environmental conditions is resolved by Incremental Conductance Method. The Incremental Conductance can easily determine whether the Maximum Power Point Tracking has reached the MPP and when it reaches the MPP, it stops perturbing. If the condition is not matched, the direction of operation of maximum power point will perturbed according to relation of $\mathrm{dI} / \mathrm{dV}$ and $-\mathrm{I} / \mathrm{V}$ given by equations 6-8 [15,16]. Figure 8 given below plot between Power and voltage for IC Algorithm.

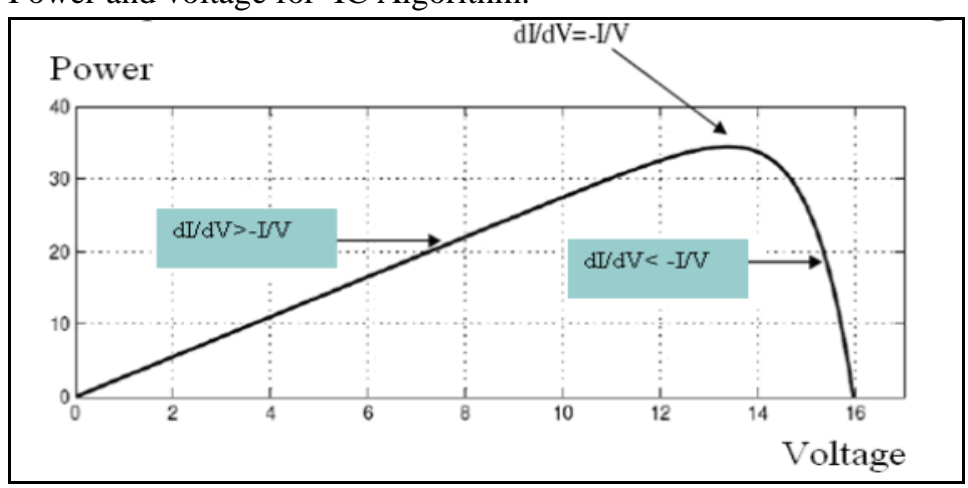

Figure 8 Power versus Voltage Curve for Incremental Conductance algorithm [16]

As depicted from figure 8, at MPP the slope of photovoltaic array is 0 . This method helps the utmost usage of the assumption that proportion of change in output $(\mathrm{O} / \mathrm{P})$ conductance is same as that of negative output instantaneous conductance. As,

$\mathrm{P}=\mathrm{VI}$

Chain rule for derivatives is applied

$\mathrm{dp} / \mathrm{dv}=[\mathrm{d}(\mathrm{VI})] / \mathrm{dV}$ 
At MPP

$\mathrm{dP} / \mathrm{dV}=0$

Equation shown above is expressed in the terms of arraye voltage \& current:

$\mathrm{d} \mathrm{I} / \mathrm{dV}=-\mathrm{I} / \mathrm{V}$

Pulse width modulated signal of DC to DC boost converter is controlled by MPPT until the desired condition is fulfilled.• Figure 9 given below is the Simulink Model of Incremental Conductance (IC) algorithm.

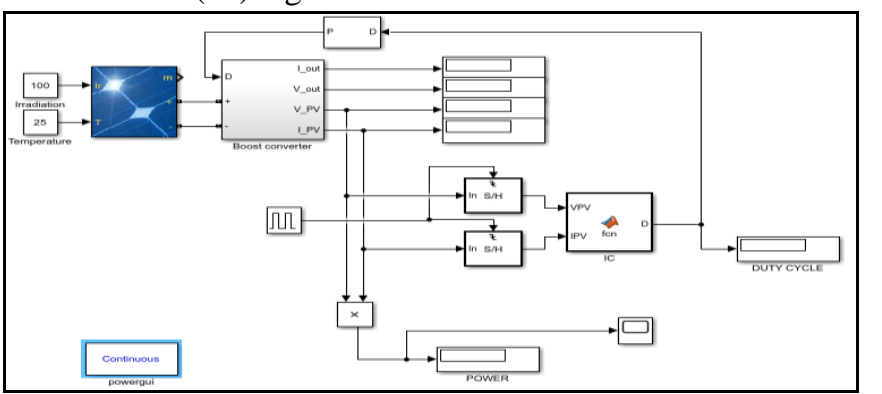

Figure 9 Simulink Model of Incremental Conductance (IC) Method

Main components used in this model are solar panel, boost converter, sample \& hold circuit, PWM generator, IC algorithm.

\section{Inverted-V Method}

Standard irradiation and temperature are red and blue curve in the figure 10 shown below is:

RED :- irradiation is 1000 and temperature is 25 degree BLUE :- irradiation is 1000 and temperature is 45 degree Now, the red dot on the curve is MPP point

At 25 degree :- red dot is on $29 \mathrm{~V}$ voltage and $213 \mathrm{~W}$ power

At 45 degree :- red dot is on $26.34 \mathrm{~V}$ voltage and $195.4 \mathrm{~W}$ power

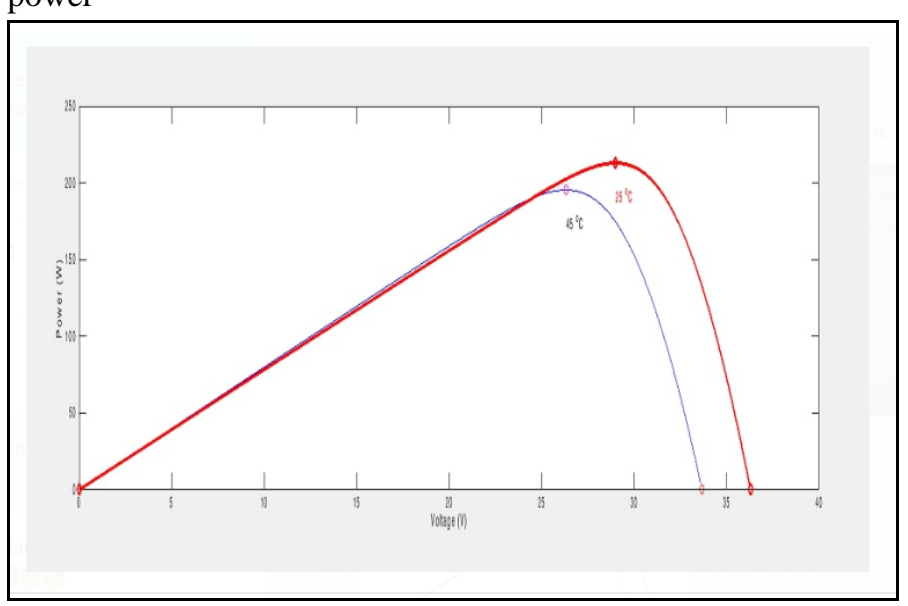

Figure $10 \mathrm{P}-\mathrm{V}$ characteristics of a Panel

From figure 10 , it has been observed that

characteristics on the left and right side of MPP are approximate straight lines and their intersection point is quite close to the actual Maximum Power Point.
If a duty cycle is obtained near to the MPP, then MPP can be obtained much faster even with a small perturbation value

This will faster the response time and decrease the amplitude of oscillations around MPP.

In the process of finding an initial duty cycle this is supposed to be as close to the duty cycle corresponding to MPP.

For this Proceed by finding the intersection of the approximate straight line on the left and right side of MPP and measure power obtained from the panel by setting the duty cycle corresponding to that intersection point and measure its closeness to the MPP.

Use two points form to determine the equation of the approximate line.

Two Points corresponding to the left side of MPP are $(0,0)$ and $\left(\mathrm{V}_{1}, \mathrm{P}_{1}\right)$

The equation of the line at the left side of MPP is

$P=\frac{P_{1}}{V_{1}} \mathrm{~V}$

Two Points corresponding to the right side of MPP are $\left(\mathrm{V}_{2}, \mathrm{P}_{2}\right)$ and $\left(\mathrm{V}_{\mathrm{oc}}, 0\right)$

$P=\frac{P_{2} V-P_{2}, V_{0 c}}{V_{2}-V_{o c}}$

Voltage corresponding to the intersection point is;

$$
V=\frac{P 2, V o c, V 1}{P 2 . V 1+P 1, V o c-P 1, V 2}
$$

Intersection point $\mathrm{V}$ is now calculated with the help of intersection of $\mathrm{P}$ according to equation 15 .

Input and output voltage of boost converter are related as

$V_{o}=\frac{V i n}{1-\alpha}$

To calculate duty cycle at the intersection point there is need to find the value of output voltage of the boost converter at the point of intersection. Panel is a DC device so it can be assumed as resistive load.

Therefore, Vo can also be calculated by the following equation;

$V_{0}=\sqrt{P \cdot R_{\text {out }}}$

Rout can be calculated as

$R_{\text {out }}=\frac{V_{10}{ }^{2}}{P_{1}}$

Where $V_{10}=$ output voltage of boost converter at V1.

The proposed algorithm has been implemented on MATLAB with the built in PV array Simulink block. 
Duty cycle at point V1 and P1 was 0.9 and at V2 and P2 was 0.1

The test was carried out at various irradiation and temperature details of which are summarized below;

Table 1 Result of Inverted -V method

\begin{tabular}{|c|c|c|c|c|c|}
\hline $\begin{array}{l}\text { Irradiatio } \\
\text { n }\end{array}$ & $\begin{array}{l}\text { Temperatur } \\
\mathrm{e}\end{array}$ & $V_{\text {OC }}$ & Pmpp & $\begin{array}{l}\text { Duty } \\
\text { Cycle }\end{array}$ & $\begin{array}{l}\text { Power at } \\
\text { calculate } \\
\text { d duty } \\
\text { cycle }\end{array}$ \\
\hline 1000 & 25 & $\begin{array}{l}36.3 \\
3\end{array}$ & $\begin{array}{l}213.1 \\
5\end{array}$ & $\begin{array}{l}0.79 \\
7\end{array}$ & 212.82 \\
\hline 1000 & 45 & $\begin{array}{l}33.6 \\
8\end{array}$ & $\begin{array}{l}195.4 \\
2\end{array}$ & $\begin{array}{l}0.80 \\
7\end{array}$ & 195.21 \\
\hline 500 & 25 & $\begin{array}{l}35.2 \\
2\end{array}$ & 108 & $\begin{array}{l}0.71 \\
3\end{array}$ & 108 \\
\hline 100 & 25 & $\begin{array}{l}32.8 \\
1\end{array}$ & 20.68 & $\begin{array}{l}0.37 \\
3\end{array}$ & 20.68 \\
\hline
\end{tabular}

\section{Parallel String -1; Series String-1}

Figure 11 given below is the Simulink Model of Inverted-V Method. The components used in this model is solar panel, boost converter, sample \& hold circuit, PWM generator, Inverted-V algorithm, counter, delay adjust.

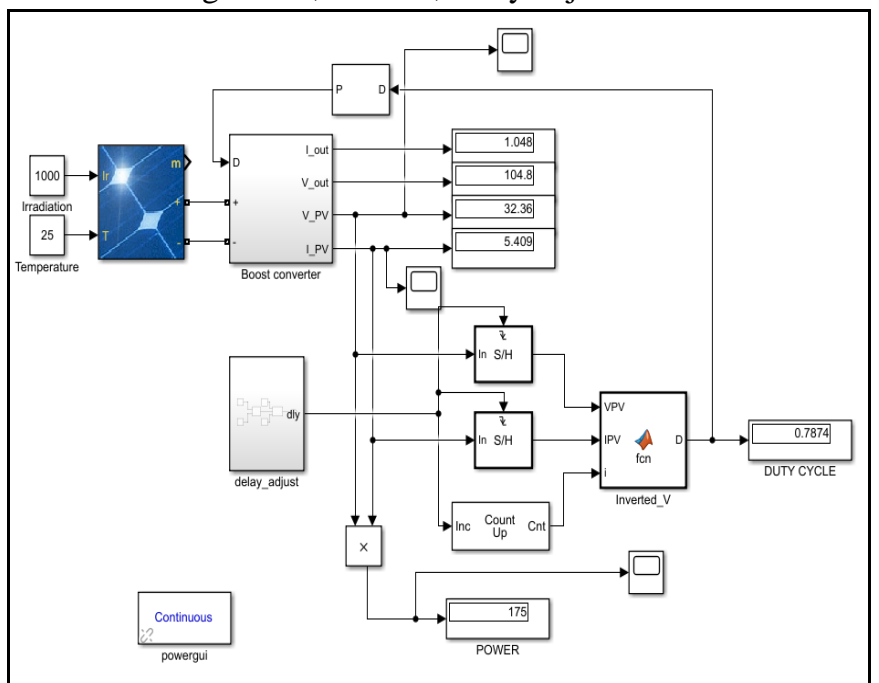

Figure 11 Simulink Model of Inverted V Method

\section{Simulation Results}

The comparison among various MPPT algorithms is carried out on four characteristic parameters namely voltage, current, power of Photovoltaic module and duty cycle of the converter which are graphically represented by Figures 12-23
Table 2 and 3 represents design parameters of boost converter and Photovoltaic array respectively.

Table 2 Boost converter Design Parameters

\begin{tabular}{|l|l|}
\hline Input Inductance & $400 \mathrm{mH}$ \\
\hline Input Filter Capacitance & $100 \mathrm{uF}$ \\
\hline Output Filter Capacitance & $100 \mathrm{Uf}$ \\
\hline Load & $100 \mathrm{ohms}$ \\
\hline Switching frequency & $5 \mathrm{kHz}$ \\
\hline
\end{tabular}

Table 3 PV Array Design Parameters

\begin{tabular}{|l|l|}
\hline Open Circuit Voltage & $36.33 \mathrm{~V}$ \\
\hline Short Circuit Current & $7.84 \mathrm{~A}$ \\
\hline $\mathrm{V}_{\mathrm{mpp}}$ & $29.00 \mathrm{~V}$ \\
\hline$I_{\mathrm{mpp}}$ & $7.35 \mathrm{~A}$ \\
\hline Max. power & $213.15 \mathrm{~W}$ \\
\hline
\end{tabular}

Among all the five methods "Inverted-V" method was found to have lowest amplitude of oscillation around MPP and lowest response time to reach MPP which shows that it has least losses (higher efficiency) and is more prompt than the other four methods. Moreover, P\&O, HC and IC had considerable amount of oscillation around MPP and EA-P\&O after three larger oscillations switches low to a low perturbation step which lowers the amplitude of oscillation around MPP furthermore which shows that EA-P\&O must be more efficient than the other three (P\&O, HC and IC). Equation (20) is used to calculate efficiency of the methods.

$\mathrm{\eta}=\frac{\text { Pavg at mpp }}{\text { Pmax of } P V \text { module }}$

Pavg at MPP can be found as

Pavg at mpp $=\frac{\int P d t}{\int d t}$

Figures 12-14 given below are the power curves of Perturb and observe, Incremental Conductance and Inverted-V algorithm. All these curves of all algorithms are between power and time. 


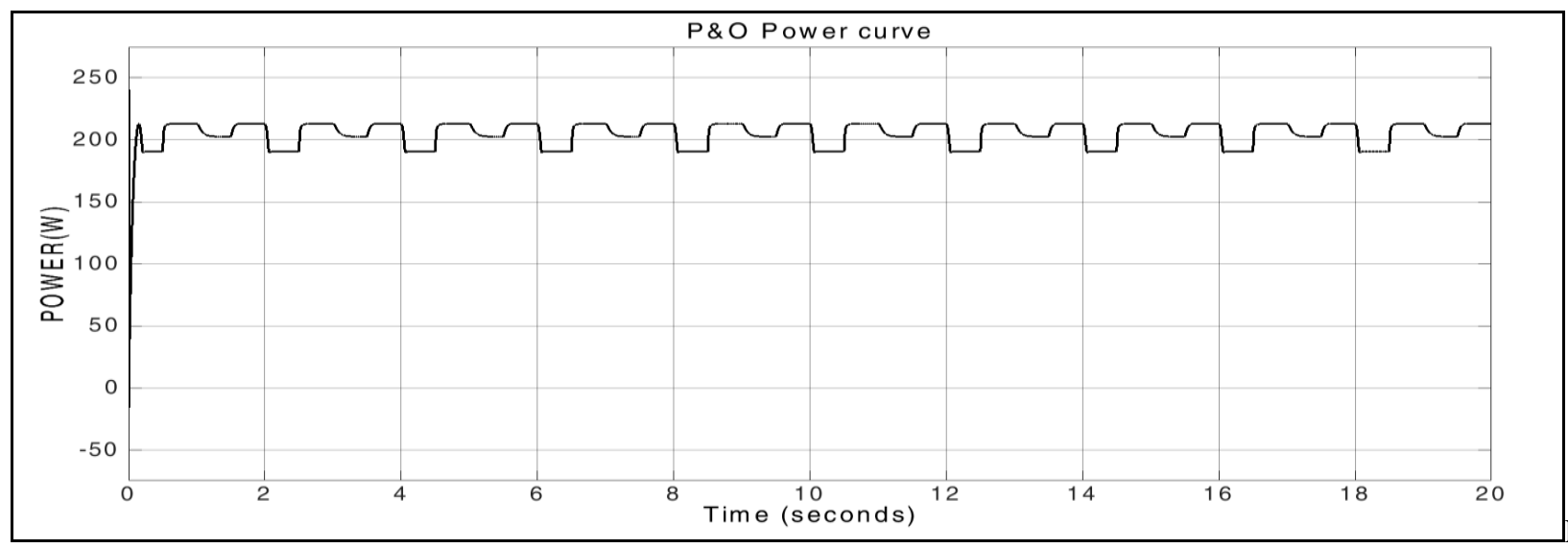

Power curve for P\&O Method

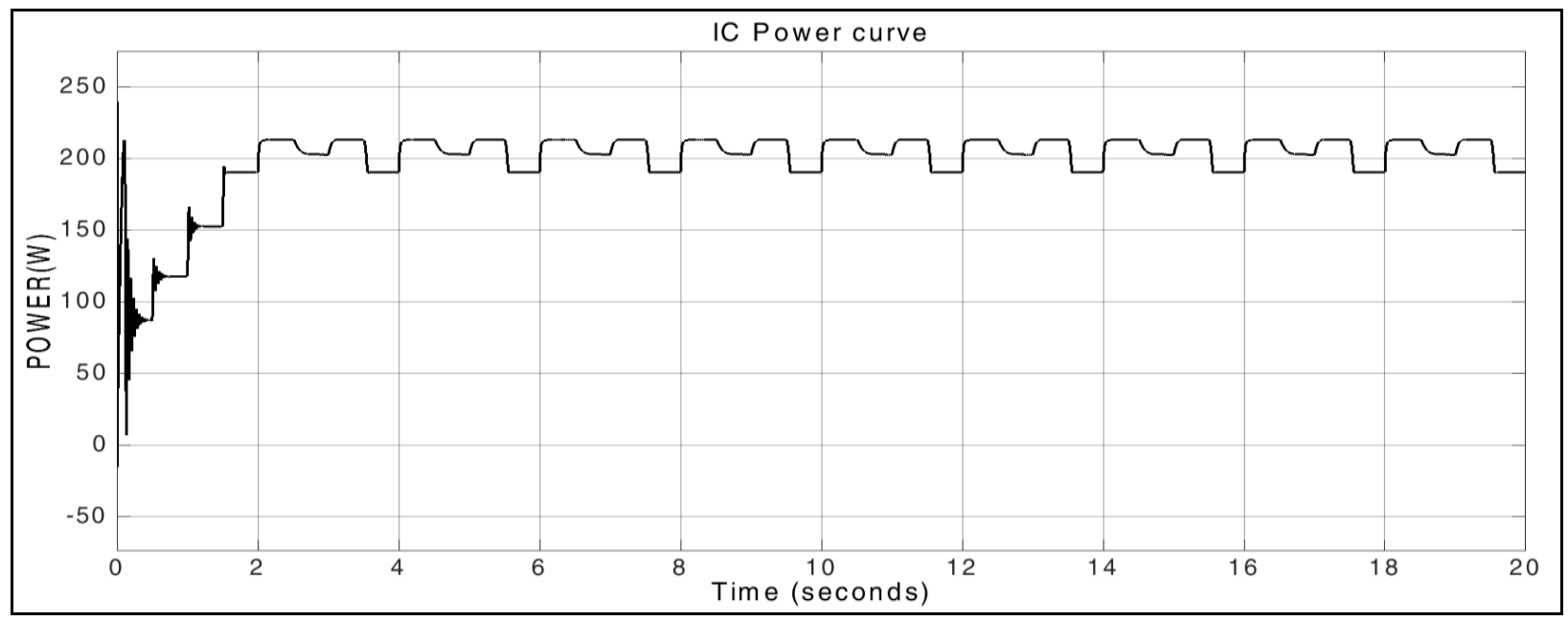

Figure 13 Power Curve for IC method

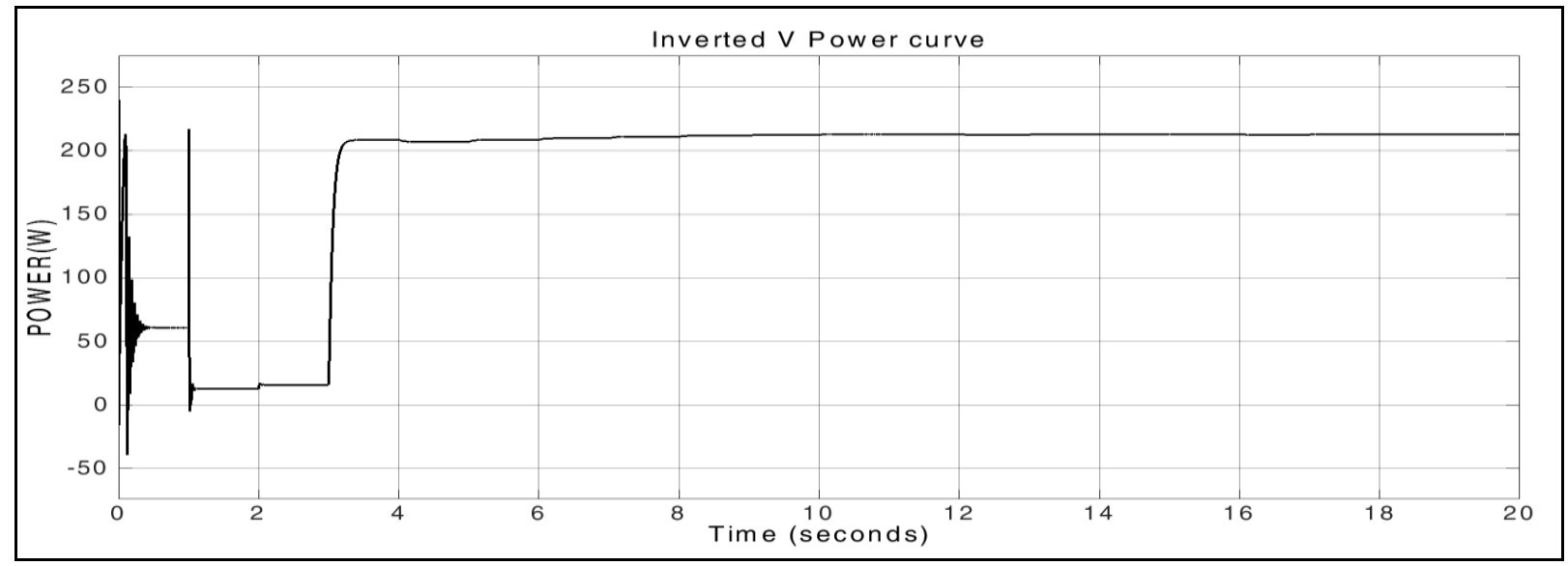

Figure 14 Power Curve of Inverted-V method

comparatively low oscillations around MPP as compared to

Now, comparing the power curve of all the methods it is observe that Incremental Conductance and Perturb \& Observe Method has the highest amplitude of oscillations around the MPP, Effective Advanced Perturb \&Observe has observe, Incremental Conductance, Inverted-V Method 


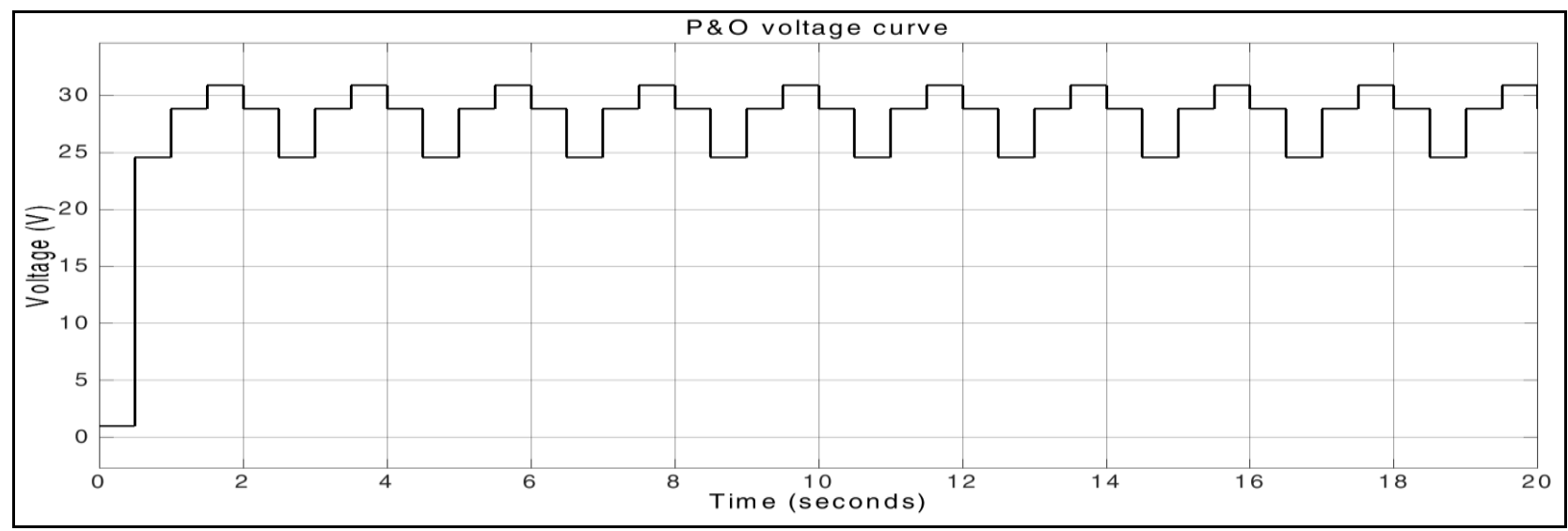

Figure 15 Voltage curve for P\&O Method

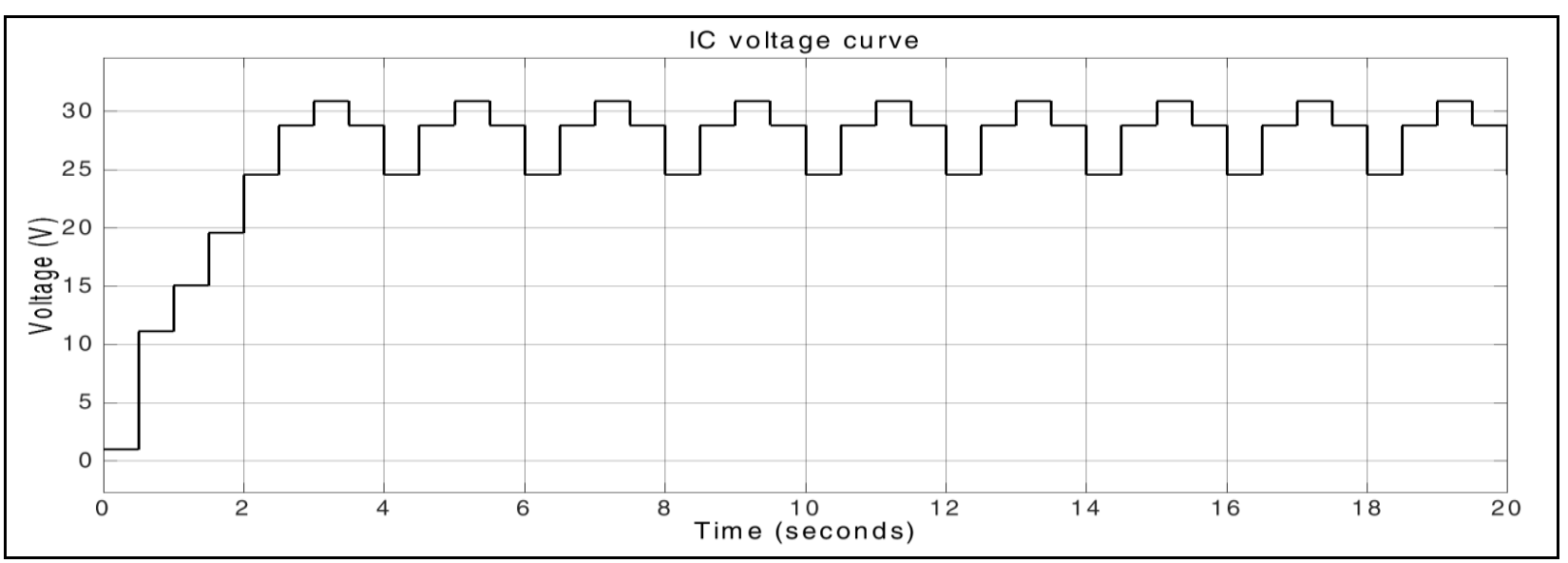

Figure 16 Voltage curve for IC method

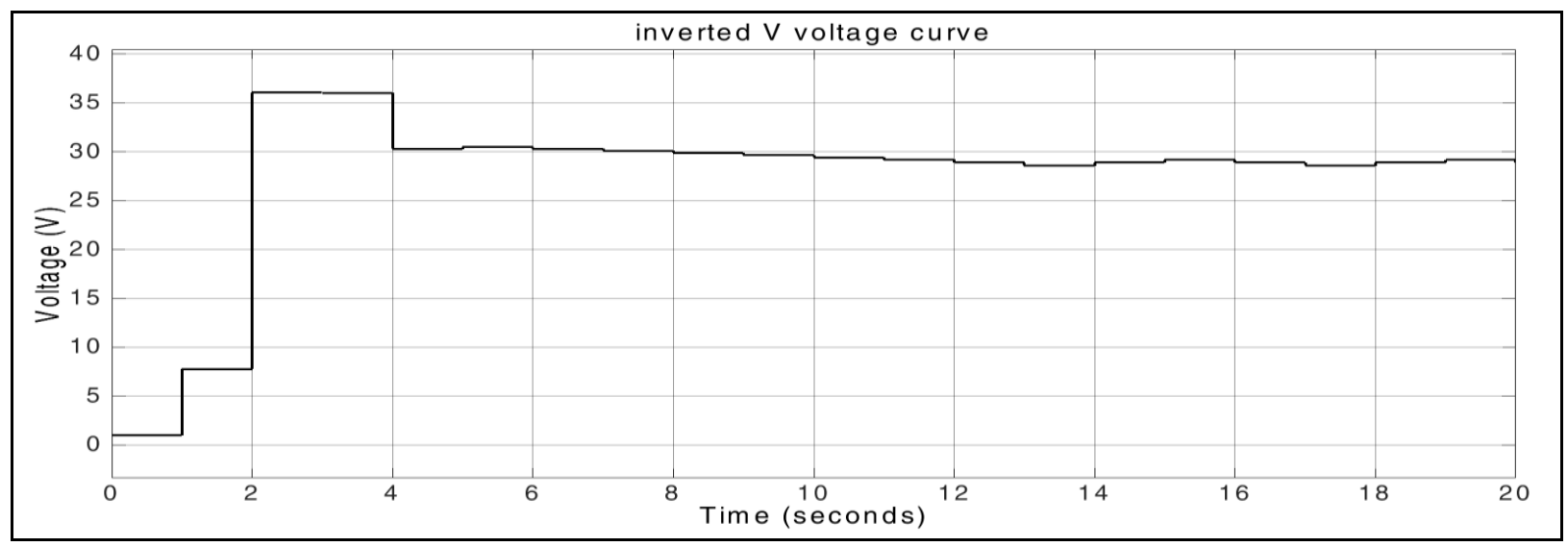

Figure 17 Voltage curve for Inverted-V method

Now, comparing the voltage curve of all the methods it has been observed that Incremental Conductance and Perturb \& Observe Method has the highest amplitude of oscillations around the MPP, Effective Advanced Perturb \&Observe has comparatively low oscillations around MPP as compared to the latter three methods, Inverted-V method is observed to have the lowest amplitude of oscillations around the MPP. Figures 18-20 given below are the current curves of Perturb \& observe, Incremental Conductance, Inverted-V Method. 


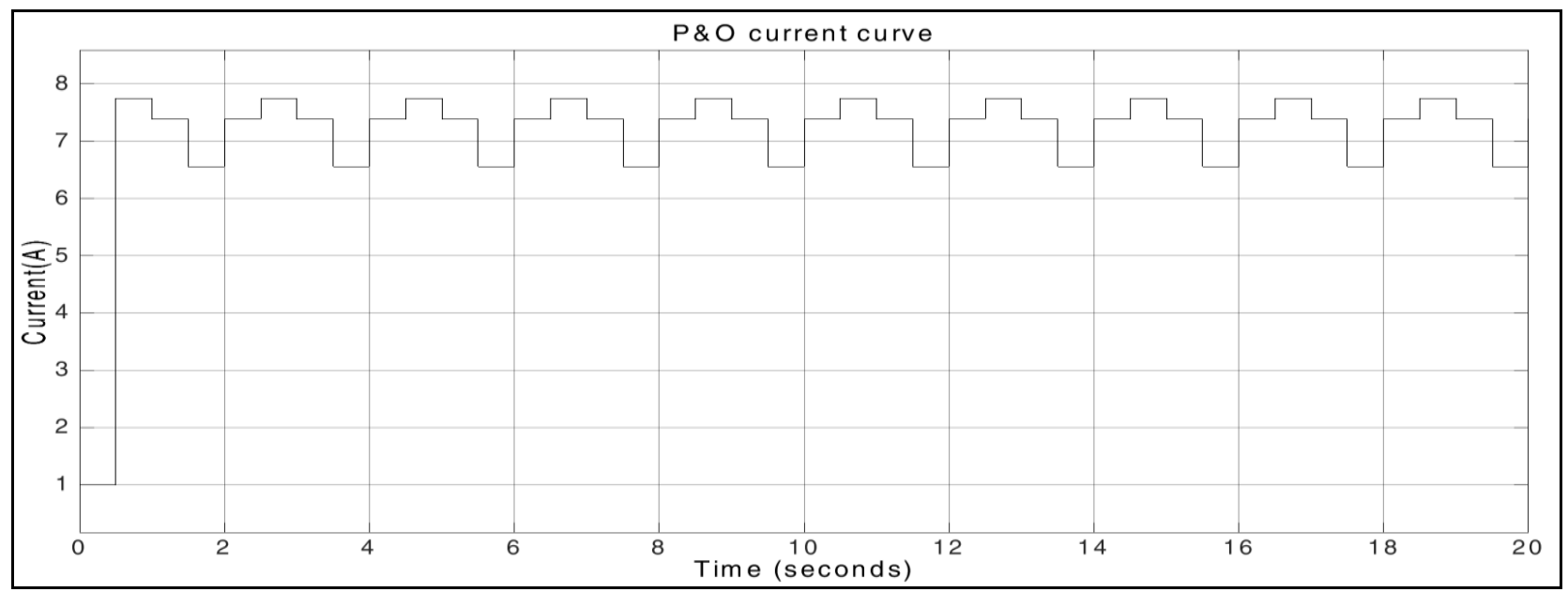

Figure 18. Current curve for P\&O Method

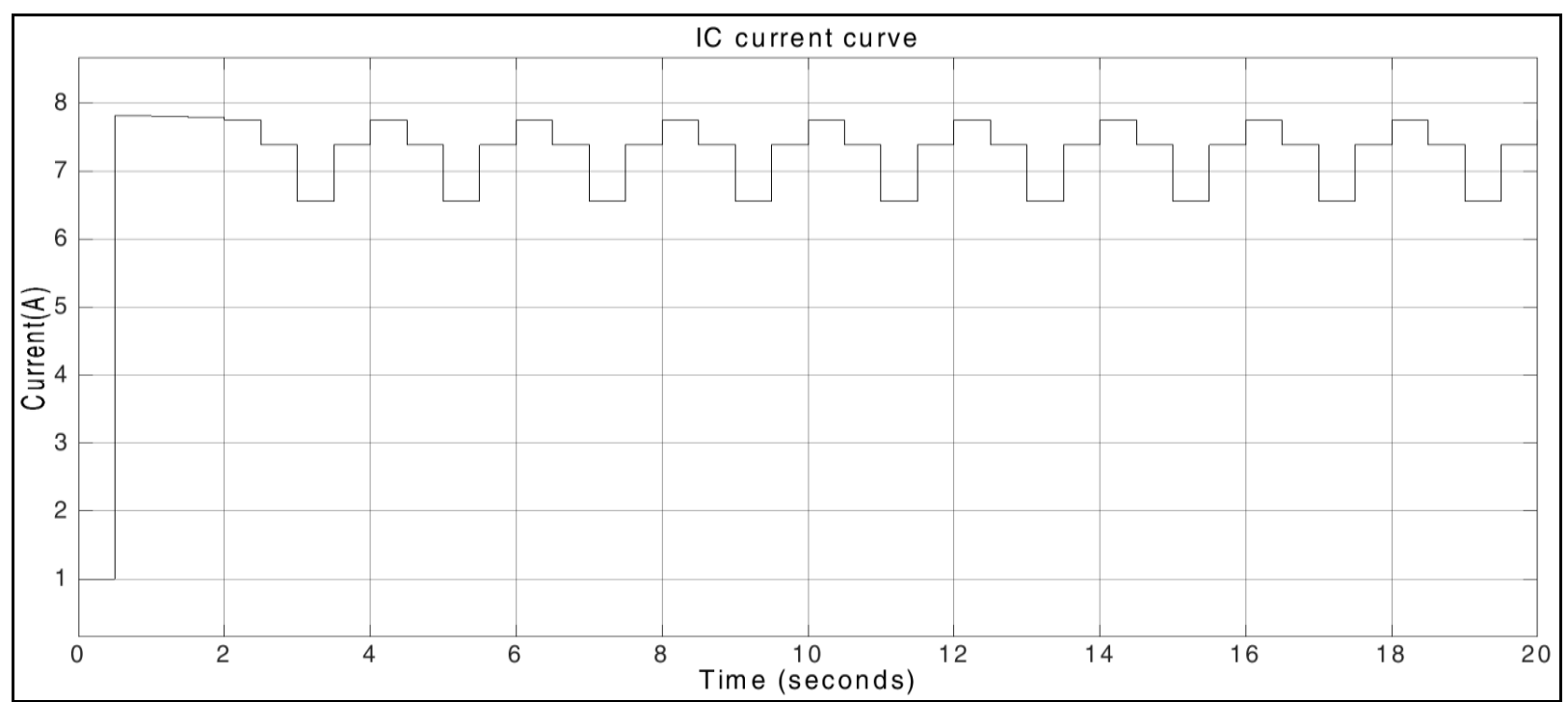

Figure 19 Current curve for IC method

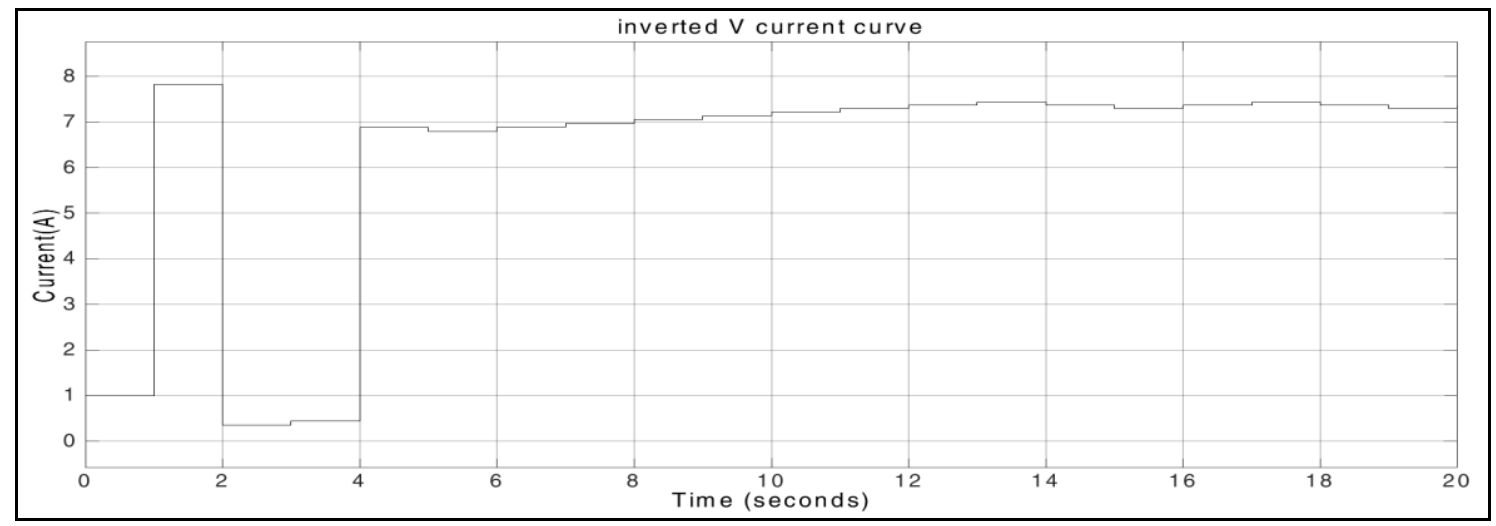

Figure 20 Inverted-V Current curve

By comparing the current curve of all the methods it has been observed that Incremental Conductance and Perturb \& Observe Method has the higher amplitude of oscillations as compared to the Inverted-V method around the MPP.
Figures 21-23 given below are the duty cycle curves of Perturb \& observe, Incremental Conductance, Inverted-V Method. 


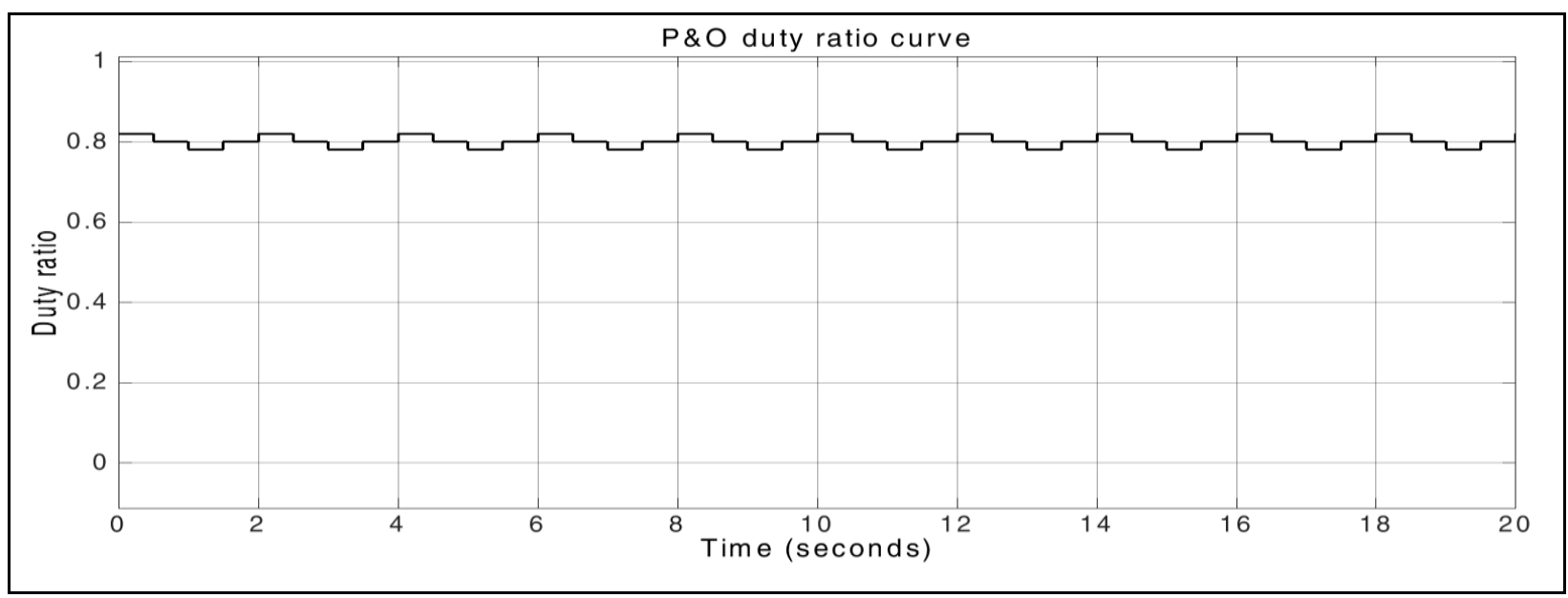

Figure 21 Duty Cycle curve of P\&O

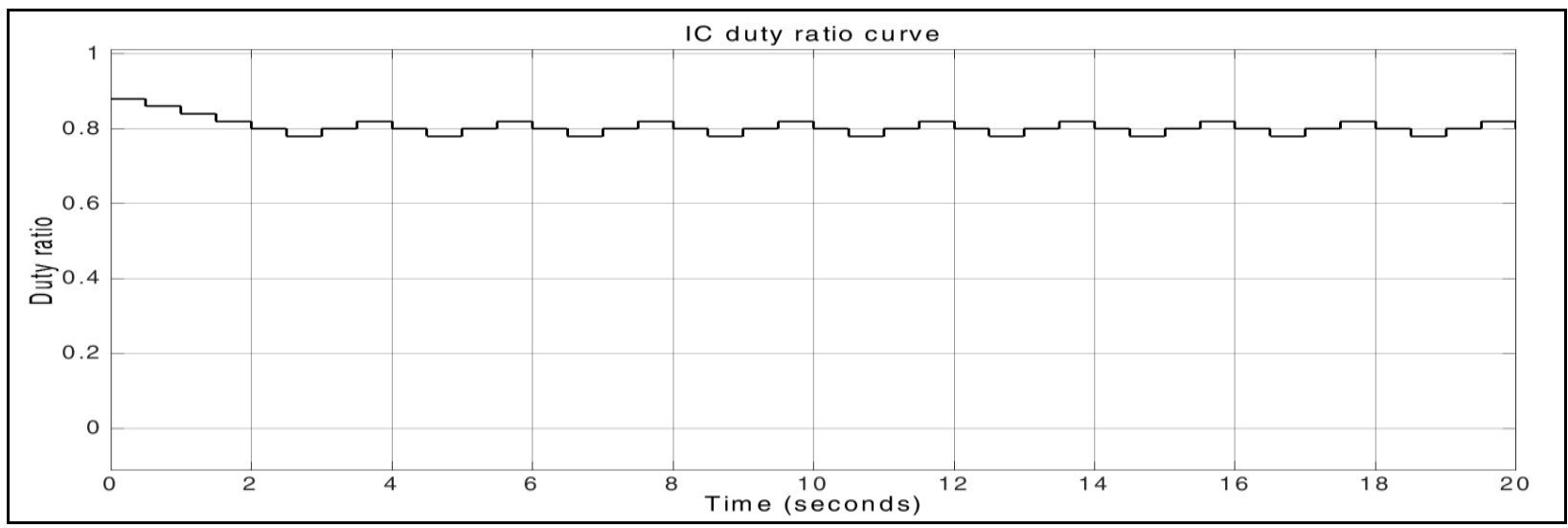

Figure 22 Duty Cycle curve of IC

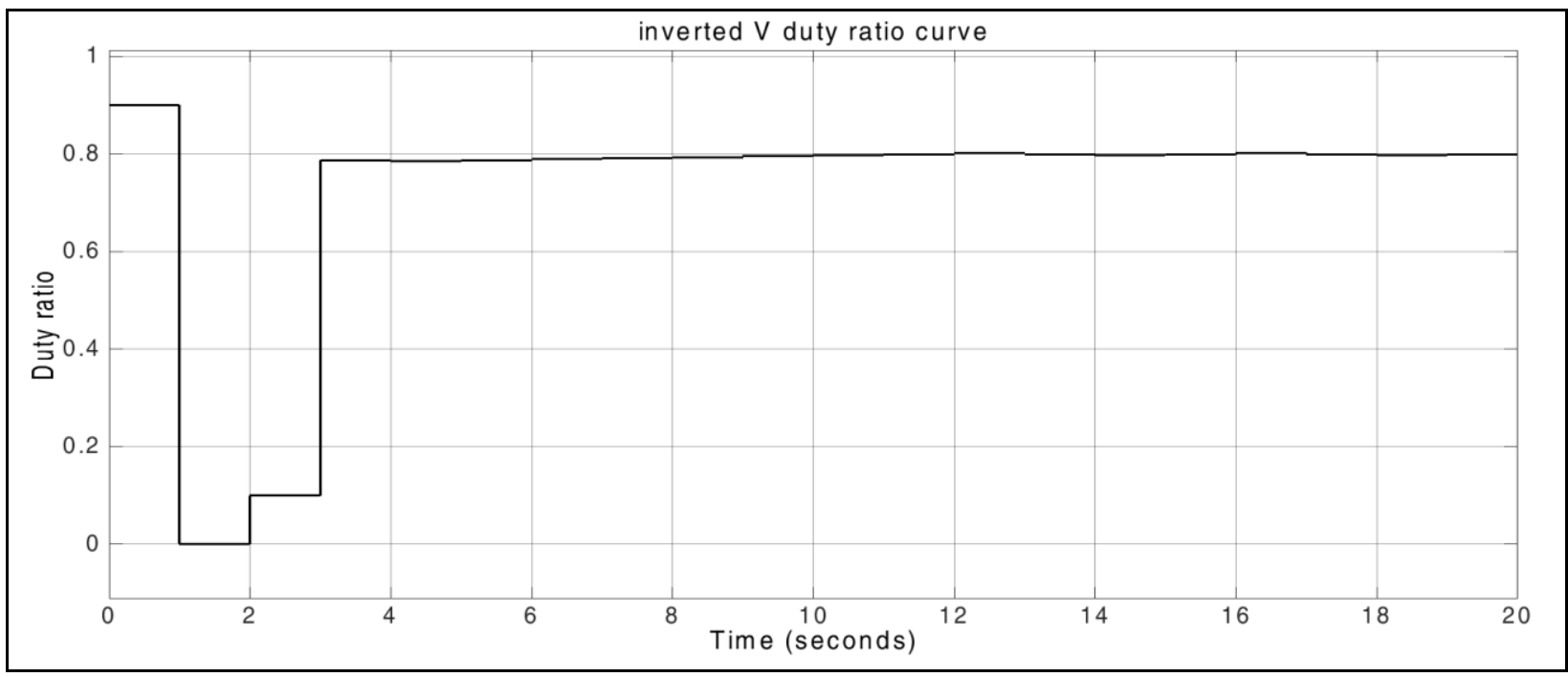

Figure 23 Duty Cycle Curve of Inverted-V method

As depicted from figures 21-23, duty cycle of Incremental Conductance and Perturb \& Observe Method has more oscillations as compared to the Inverted-V method around the point of MPP. 
and Perturb \& Observe Method has the higher amplitude of oscillations as compared to the Inverted-V method around the point of maximum power.

Similarly observing voltage, current and duty cycle curve, it has been found that the amplitude of oscillations is lowest in the Inverted-V method for considering all the four characteristics parameter.

Table 4 Efficiency of Different MPPT Methods

\begin{tabular}{|l|l|}
\hline MPPT Method & Efficiency (\%) \\
\hline P\&O & $94.58 \%$ \\
\hline IC & $94.58 \%$ \\
\hline Inverted-V Method & $99.81 \%$ \\
\hline
\end{tabular}

Moreover, in the inverted-V method, the operation around MPP is achieved at the faster rate as compared to all the other four methods. Comparison of efficiency for different MPPT is given in table 4. As depicted from table 4, it is concluded that efficiency of Inverted-V method is higher than Perturb \&Observe, Incremental Conductance. From the analysis of all parameters, it has been concluded that Inverted $\mathrm{V}$ method performs better as compared to Perturb \& Observe and Incremental Conductance method for maximum power point tracking.

\section{References}

[1]. M.C. Argyrou, P. Christodoulides and S.A. Kalogirou, \& Kalogirou, (2018 ) "Modeling of a photovoltaic system with different MPPT techniques using MATLAB/Simulink, IEEE International Energy Conference (ENERGYCON),Limassol, , 1-6.doi: 10.1109.

[2]. A.Gaga,F. Errahimi and N.Es- Sbai (2014), , "Design and implementation of MPPT solar system based on the enhanced P\&O algorithm using Labview,"2014 International Renewable and Sustainable Energy Conference (IRSEC), Ouarzazate, 203-208.doi: 10.1109.

[3]. S.Xiao and R.S. Balog, "An improved adaptive perturb \& observe maximum power point tracking technique (2018),"2018 IEEE Texas Power and Energy Conference (TPEC) ,College Station,TX, ,pp. 1-6.doi: 10.1109

[4]. A.Durgadevi, S.Arulselvi and S.P. Nataranjan,(2011) "Study and implementation of Maximum Power Point Tracking (MPPT) algorithm for Photovoltaic systems, Newport Beach,CA,pp.240-245.doi:10.1109.

[5]. A.S. Ahmed,B.A. Abdullah and W.G.A Abdelaal, (2016)“MPPT algorithms: Performance and

Copyright $(\subset)$ Authors evaluation," 11th International Conference on Computer Engineering \&Systems(ICCES),Cairo, 6,pp. 461-467.doi: 10.1109.

[6]. M.A.G. de Brito,L.P. Sampaio,L.G.junior and C.A. Canesin, (2011) "Evaluation of MPPT techniques for photovoltaic applications," IEEE International Symposium on Industrial Electronics,Gdansk,2011,PP.1039-1044.doi: 10.1109.

[7]. O.Singh and S.K. Gupta (2018), “A review on recent MPPT techniques for photovoltaic system”, IEEMA Engineer Infinite Conference(eTECHNxt), New Delhi,2018,pp. 1-6.

[8]. M. A. $\mathrm{G}$ de Brito,L Galotto,L.P.Sampio,G.d.A.eMelo and C.A.Canesin (2013) "Evaluation of the Main MPPT Techniques for Photovoltaic Applications," in IEEE Transactions on Industrial Electronics, vol. 60),pp. 1156-1167,March 2013.

[9]. A.K.Gupta and R.Saxena,(2019), "Review on widely used MPPT techniques for PV applications,' 2016 International Conference on Innovation and Challenges in Cyber Security(ICICCS-INBUSH),noida ,pp. 270-273.doi: 10.1109 .

[10]. A. Kchaou,A. Naamane ,Y.Koubaa and N.K.M'Sirdi(2016) , “Comparative study of different MPPT techniques for a Stand alone PV system"2016 , 17th International Conference on Sciences and Techniques of Automatic Control and Computer Engineering (STA),Sousse,2016,pp. 629634.doi: 10.1109 .

[11]. S.KumarRoy,S. Hussain and M.A. Bazaz,"Implementation of MPPT techniques for solar PV system using ANN," 2017 Recent Developments in Control, Automation\& Power Engineering (RDCAPE),Noida ,pp. 338-342.doi: 10.1109.

[12]. X.Li, H.Wen and Y. Hu, (2016) "Evaluation of different maximum power point tracking(MPPT) techniques based on practical meterological data", IEEE International Conference on Renewable Energy Research and Applications(ICRERA),Birmingham,2016,pp.696701.doi: 10.1109 .

[13]. B.Subudhi and R. Pradhan (2013), “A Comparative Study on Maximum Power Point Tracking Techniques for Photovoltaic Power Systems,"in IEEE Transactions on Sustainable Energy , 4,(1), pp. 89-98,Jan.2013,doi:10.1109.

[14]. W.Xiao.A.Elnosh,V.Khadkikar and H. Zeineldin, (2011) , "Overview of maximum power point tracking technologies for photovoltaic power 
systems,"'IECON 2011-37 th Annual Conference of the IEEE Industrial Electronics Society,Melbourne,VIC,2011,PP. 3900-3905.doi: 10.1109 .

[15]. L.Omine,M.Brito and J.Onofre,(2018) "Analysis of Hybrid MPPT Techniques for Photovoltaic Systems,” 2018A. RezaeeJordehi,"Maximum power point tracking in photovoltaic (PV) systems: A review of different approaches",pp. 1127-1138.

[16]. J.SuryaKumari,Ch. SaiBabu,A. KamalakarBabu, (2012) "Design and Analysis of P\&O and IP\&O MPPT Techniques for Photovoltaic System", International Journal of Modern Engineering Reseaarch (IJMER)Vol. 2, pp-2174-2180. 